\title{
True Resistant Hypertension among Treated Hypertensive Black Patients. A Clinical-Based Cross-Sectional Study
}

\author{
Diane Kiese Kuntonda ${ }^{1}$, François Bompeka Lepira ${ }^{2 *}$, Yves Lubenga ${ }^{1}$, \\ Jean Robert Risassi Makulo², Aliocha Nkodila ${ }^{3}$, Noel Otshudi', Trésor Mvunzi ${ }^{1}$, \\ Dominique Mupepe ${ }^{1}$, Georges Ngoyi ${ }^{1}$, Fabien Kintoki ${ }^{1}$, Eulhetère Vita Kintoki ${ }^{1}$, \\ Jean René M'buyamba-Kabangu ${ }^{1}$
}
${ }^{1}$ Division of Cardiology, University of Kinshasa Hospital, Kinshasa School of Medicine, University of Kinshasa, Kinshasa, The Democratic Republic of the Congo
${ }^{2}$ Division of Nephrology-Dialysis and Hypertension, University of Kinshasa Hospital, Kinshasa School of Medicine, University of Kinshasa, Kinshasa, The Democratic Republic of the Congo
${ }^{3}$ Centre Médical Cité des Aveugles Mont Ngafula, Kinshasa, The Democratic Republic of the Congo
Email: *lepslepira@yahoo.fr, fr.lepira@gmail.com

How to cite this paper: Kuntonda, D.K., Lepira, F.B., Lubenga, Y., Makulo,, J.R.R., Nkodila, A., Otshudi, N., Mvunzi, T., Mupepe, D., Ngoyi, G., Kintoki, F., Kintoki, E.V. and M'buyamba-Kabangu, J.R. (2020) True Resistant Hypertension among Treated Hypertensive Black Patients. A Clinical-Based Cross-Sectional Study. World Journal of Cardiovascular Diseases, 10, 278-293. https://doi.org/10.4236/wjcd.2020.105026

Received: March 21, 2020

Accepted: May 5, 2020

Published: May 8, 2020

Copyright ( 2020 by author(s) and Scientific Research Publishing Inc. This work is licensed under the Creative Commons Attribution International License (CC BY 4.0).

http://creativecommons.org/licenses/by/4.0/ (c) (i) Open Access

\section{Abstract}

Background and Objective: 24-h ambulatory blood pressure monitoring (ABPM) aids to precisely identify patients with true resistant hypertension (tRH). The present study was aimed to assess the frequency and correlates of tRH among patients with clinically suspected RH. Methods: Medical records of treated hypertensive patients referred in four healthcare centers for BP control evaluation by $24-\mathrm{h} \mathrm{ABPM}$ were reviewed to assess the prevalence of tRH. Inclusion criteria were age $\geq 18$ years, clinical diagnosis of RH. Data on demographic, clinical, laboratory, 2D-echocardiography and 24-h ABPM parameters were retrieved from patient's medical records. True RH (tRH) was defined as office blood pressure (BP) $\geq 140 / 90 \mathrm{mmHg}$ and 24-h ambulatory $\mathrm{BP} \geq 130 / 80 \mathrm{mmHg}$. Simple and multiple linear regression analyses were used to assess factors associated with systolic $\mathrm{BP}$ (SBP) as a proxy of $\mathrm{RH}$ among patients with tRH. $\mathrm{P}<0.05$ defined the level of statistical significance. Results: Of 636 patients referred for BP control evaluation by 24-h ABPM, 75 (11.7\%) had suspected RH by office BP measurements. After 24-h ABPM, pseudo or apparent $\mathrm{RH}(\mathrm{aRH})$ and tRH were observed in $15(2.3 \%)$ and 60 $(9.4 \%)$ patients, respectively. BMI $(\mathrm{p}=0.007)$ and blood glucose $(\mathrm{p}=0.024)$ were positively associated with SBP whereas a negative association was observed with eGFR ( $\mathrm{p}=0.022)$ among tRH hypertensive patients in multiple regression analysis. Conclusion: True $\mathrm{RH}$ was a common finding among pa- 
tients with clinical RH and associated with obesity and silent target organ, especially kidney dysfunction. The present study highlights the diagnostic and prognostic importance of 24-h ABPM among patients with clinical RH.

\section{Keywords}

True Resistant Hypertension, 24-h ABPM, Prevalence, Determinants, Black Africans

\section{Introduction}

In sub-Saharan Africa (SSA), very low rates of blood pressure (BP) control may predict an increased prevalence of resistant hypertension (RH) across the continent [1]. Indeed, $\mathrm{RH}$, defined as failure to achieve $\mathrm{BP}$ to target despite adherence to appropriate treatment with full doses of at least 3 drug regimens including a diuretic [2], is a life-threatening medical condition associated with a fourfold increased risk for cardiovascular events compared with patients achieving BP targets [3]. Unfortunately, few studies on the epidemiology and management of RH are available in SSA [1]. A recent meta-analysis reported that out of 259 studies retrieved from the medical literature, only 4 studies from SSA (Burkina Faso, Cameroon, Lesotho and Nigeria) were included in the review [1]. Although the definition of RH was not similar across studies, the overall pooled prevalence of RH was $12.1 \%$ (95\% CI $8.0 \%$ to $17.7 \%$ ) [1]. Therefore, studies from other SSA countries using 24-h ambulatory blood pressure monitoring (ABPM) are awaited to better determine the burden of $\mathrm{RH}$ and associated risk factors across the continent for their optimal management and control [1]. The recognition and identification of individuals with $\mathrm{RH}$ is of particular importance, given the fact that they may require further diagnostic evaluation for specific interventions [4].

As the diagnosis of $\mathrm{RH}$ is based on office $\mathrm{BP}$ measurements, its prevalence may be influenced by the white coat phenomenon [5] [6]. In this regard, previous studies have found that about one third of subjects with clinically suspected RH have indeed "apparent or pseudo-resistant" hypertension (aRH) (office $\mathrm{BP} \geq 140 / 90 \mathrm{mmHg}$ and $24-\mathrm{h} \mathrm{ABPM}<130 / 80 \mathrm{mmHg}$ ) when using 24-h ABPM. Thus, 24-h ABPM aids to precisely identify subjects with "true" $\mathrm{RH}$ (tRH) (office $\mathrm{BP} \geq 140 / 90 \mathrm{~mm} \mathrm{Hg}$ and 24-h ambulatory BP $\geq 130 / 80 \mathrm{~mm} \mathrm{Hg}$ ) [6]. ABPM, a technique of obtaining automated brachial BP measurements at fixed time intervals, during a 24-hour period away from a medical environment, represents a more "realistic" approach to BP assessment. It involves measurement of BP during the usual daily activities and sleep and estimates more accurately the overall hemodynamic load and $\mathrm{BP}$ variability [6].

In the Democratic Republic of the Congo (DRC), the prevalence of hypertension is estimated to be of $30 \%-40 \%$ [7] [8] [9] and associated with an increased 
cardiovascular (CV) morbidity and mortality [10] due, in a substantial part, to lower BP control rates in the general population [6] [7] [8] as well as in-hospital setting [11]. Lower rates of BP control highlight the need to study RH and characterize its phenotypes to avoid the overtreatment of patients with apparent or pseudo-RH under a context of limited resources. Since the recent availability of 24-h ABPM in some health centers in Kinshasa, studies have focused only on BP patterns and dipping status among hypertensive [12] and chronic hemodialysis [13] patients; despite the increased prevalence of uncontrolled hypertension, data on RH using 24-h ABPM are not yet available. Therefore, the present study was aimed to asses, using 24-h ABPM, the frequency and clinical profile of "true" RH (tRH) among patients with clinically suspected RH.

\section{Patients and Methods}

We reviewed medical files of all treated hypertensive patients referred to four private healthcare Centers (Ngaliema Medical Center, Kinshasa Medical Center, Diamant Medical Center and "Médecins de Nuit" Center) in Kinshasa for BP control evaluation by 24-h ABPM during the period between January 1, 2019 and September 30, 2019. Inclusion criteria were age $\geq 18$ years, office BP-based $\mathrm{RH}$, and available data on 24-h ABPM. Patients with clinical signs of secondary hypertension, incomplete medical files, atrial fibrillation and those on drugs interfering with BP like non-steroidal anti-inflammatory drugs (NSAIDs) were excluded. The study was approved by the Internal Review Board (IRB) of the University of Kinshasa Hospital and obtained the clearance of the medical staff of participating Centers. Patient's information at the visit before ABPM was extracted from their medical records using a predetermined proforma which included the patient's past medical history (duration of hypertension, family history of hypertension, alcohol intake, smoking, physical activity, use of antihypertensive agents, co-morbidities), socio-demographic (age, gender, education level), clinical (symptoms, office blood pressure, weight, and height), biochemical profile [fasting plasma glucose (FPG), blood urea nitrogen (BUN), serum uric acid, serum creatinine, total cholesterol (TC), low-density lipoprotein-cholesterol (LDL-c), high-density lipoprotein-cholesterol (HDL-c), triglycerides (TG), serum sodium and potassium, serum c-reactive protein (CRP), dipstick proteinuria, 2D-echocardiography and 24-h ABPM parameters. The data was captured by a trained and experienced member of the research team at each participating center and accuracy of data entry was checked by the principal investigator herself. Alcohol intake and smoking as well as physical activity status were retrieved from patient's medical records. Patient's BP, which was measured by attending physicians as a part of daily routine care, was captured from medical records. Hypertension was defined as BP $\geq 140 / 90 \mathrm{mmHg}$ or current use of antihypertensive agents [2]; clinically suspected $\mathrm{RH}$ as office $\mathrm{BP} \geq 140 / 90 \mathrm{mmHg}$ despite appropriate treatment with full doses of at least 3 antihypertensive drugs, including a diuretic [2]. Antihypertensive drug use was captured from medical records and classified into the following classes: renin angiotensin system inhi- 
bitors encompassing angiotensin converting enzyme inhibitors (ACEI) and angiotensin type 1 receptor blockers (ARB), calcium channel blockers (CCB), beta-blockers (BB), diuretics, central acting agents (CAA), and alpha-blockers. 24-h ABPM was performed using a commercially available system (Space Labs 90207 system). BP was recorded during the day for every 15 minutes (from 07:00 to 21:00) and every 30 minutes during the night (from 21:00 to 07:00). 24-h ABPM parameters of interest were daytime, nighttime and 24-h SBP and DBP. $\mathrm{ABPM}$ records were considered valid only if the number of $\mathrm{BP}$ recordings were at least $70 \%$ of the expected readings assessed as valid by the software analysis. True (tRH) and apparent (aRH) RH was defined as office BP $\geq 140 / 90 \mathrm{mmHg}$ and $24-\mathrm{h} A B P M \geq 130 / 80 \mathrm{mmHg}$ and office $\mathrm{BP} \geq 140 / 90 \mathrm{mmHg}$ and 24-h $\mathrm{ABPM}<130 / 80 \mathrm{mmHg}$, respectively [6]. Body mass index was calculated as weight in kilogram per square meter height $\left(\mathrm{Kg} / \mathrm{m}^{2}\right)$. Overweight and obesity were defined as $\mathrm{BMI} \geq 25 \mathrm{Kg} / \mathrm{m}^{2}$ and $\geq 30 \mathrm{Kg} / \mathrm{m}^{2}$, respectively. Increased age was defined as age $\geq 45$ and $\geq 55$ years in men and women, respectively. Diabetes was defined as fasting blood glucose $\geq 126 \mathrm{mg} / \mathrm{dL}$, or the use of antidiabetic drugs [14]. Dyslipidemia was defined as total cholesterol $\geq 200 \mathrm{mg} / \mathrm{dL}$, triglyceride $\geq$ $150 \mathrm{mg} / \mathrm{dL}, \mathrm{HDL}<40$ in men and $<50 \mathrm{mg} / \mathrm{dL}$ in women, or the use of statin [15]. Low estimated glomerular filtration rate (eGFR) was defined as estimated glomerular filtration rate (eGFR) calculated by modification of diet in renal disease (MDRD) equation $<60 \mathrm{ml} / \mathrm{min} / 1.73 \mathrm{~m}^{2}$ [16] [17]. Subclinical inflammation was defined as CRP $\geq 6 \mathrm{mg} / \mathrm{L}$. Urine dipstick test $1+$ or more defined proteinuria. Echocardiographic parameters of interest were end-systolic and end-diastolic left ventricular internal diameter (LVIDd, LVIDs), interventricular septum thickness (IVST) and posterior wall thickness (PWT) calculated from 2D guided M-mode tracing. Left ventricular mass was estimated by Devereux's formula and normalized by body surface area (LVM index) [18]. Left ventricular hypertrophy $(\mathrm{LVH})$ was defined as increased LVMI ( $\geq 95 \mathrm{~g} / \mathrm{m}^{2}$ in women and $\geq 115 \mathrm{~g} / \mathrm{m}^{2}$ in men) and classified as concentric (LVMI $\geq 115 \mathrm{~g} / \mathrm{m}^{2}$ and RWT $\geq 0.42$ ) and eccentric (LVMI $\geq 115 \mathrm{~g} / \mathrm{m}^{2}$ and RWT $<0.42$ ) [19]. Relative wall thickness was calculated as $2 \times$ PWT/LVIDd [19]. A normal dipping pattern was diagnosed when the reduction in the average SBP during the nighttime period was $>10 \%$ of mean SBP during the daytime; when this proportion was $>20 \%$, the patient was classified as an extreme dipper. Non-dipping pattern was diagnosed when the average nighttime SBP reduction was $<10 \%$ with respect to daytime values; when the mean nighttime SBP was higher than the daytime one, the patient was classified as reverse dipper [20]. Advanced hypertensive retinopathy was defined as stage 3 - 4 according to Keith and Wegener classification. Ten years global cardiovascular risk was evaluated according to the 2018 European Society of Hypertension/European Society of Cardiology (ESH/ESC) guidelines [21].

\section{Statistical Analysis}

The SPSS software (Statistical Package for the Social Sciences, version 22, SPSS 
Inc., Chicago, IL, USA) was used for statistical analysis. Baseline characteristics were summarized as mean (standard deviation) or median (interquartile range) for continuous variables and as absolute (n) and relative (in \%) frequencies for categorical variables. The association of parameters of interest with systolic blood pressure among patients with tRH was assessed using multiple linear regression analysis. $\mathrm{P}$ value $<0.05$ defined the level of statistical significance.

\section{Results}

- Frequency of true hypertension in patients with clinical resistant hypertension

In the present study (Figure 1), 636 treated hypertensive patients aged $\geq 18$ years were referred for BP control evaluation by 24-h ABPM. Of these patients, $75(11.7 \%)$ were identified as having clinical RH. After 24-h ABPM, apparent $\mathrm{RH}(\mathrm{aRH})$ and true RH (tRH) were observed in 15 (2.3\%) and 60 (9.4\%) patients, respectively.

General characteristics of tRH patients are summarized in Table 1. Their mean age and BMI were $52.1 \pm 10.1$ years and $30.0 \pm 6.0 \mathrm{Kg} / \mathrm{m}^{2}$, respectively; the median duration of hypertension was 13.0 (8.7 - 17.4) weeks. Most of them were males (56\%) and had high education level (48.3\%) (Table 1). Complaints more frequently reported were headache $(43.3 \%)$, dyspnea $(8.3 \%)$ and acute chest pain (8.3\%). Mean levels of total cholesterol, triglycerides, blood glucose, uric acid, and eGFR were $199.2 \pm 53.9 \mathrm{mg} / \mathrm{dL}, 115.3 \pm 61.8 \mathrm{mg} / \mathrm{dL}, 132.8 \pm 52.1 \mathrm{mg} / \mathrm{dL}, 7.4$ $\pm 1.7 \mathrm{mg} / \mathrm{dL}$, and $74.0 \pm 25.3 \mathrm{~mL} / \mathrm{min} / 1.73 \mathrm{~m}^{2}$, respectively; their median CRP was 6.0 (4.2 - 6.8) mg/L (Table 1). Table 2 depicts hypertension's characteristics and therapeutic regimens of $\mathrm{tRH}$ patients. Median duration of antihypertensive therapy was 13.0 (8.7 - 17.4) weeks. Antihypertensive drug classes most frequently used were calcium channel blockers (CCB) (100\%), diuretics (thiazides 98.3\%), angiotensin converting enzyme inhibitors (ACEIs) (53.3\%), angiotensin

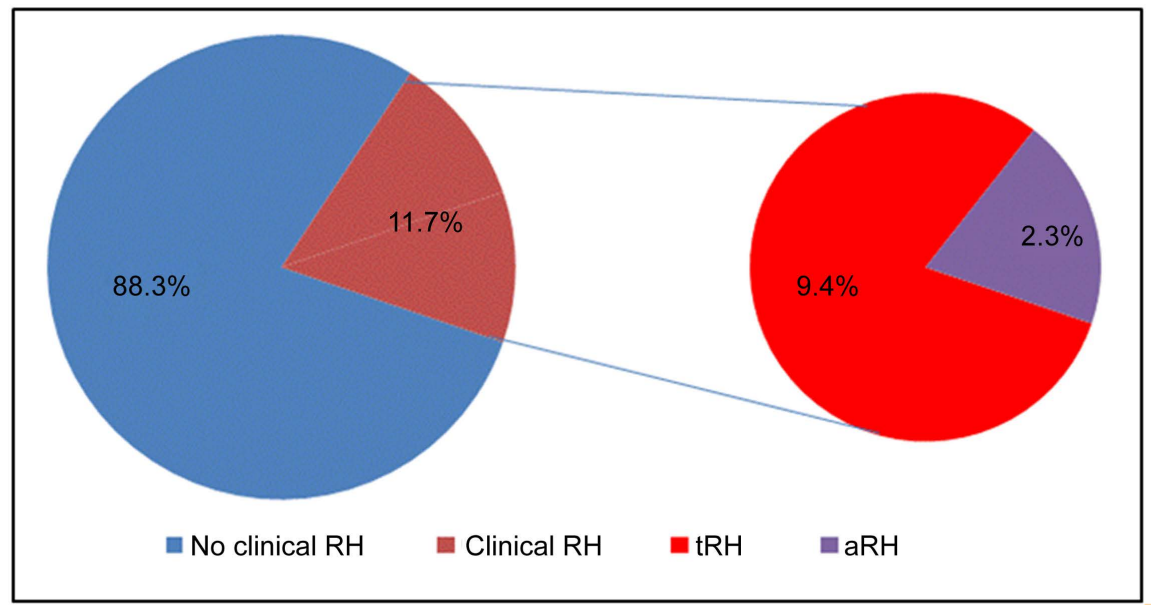

Figure 1. Frequency of clinical, apparent $(\mathrm{aRH})$ and true $(\mathrm{tRH})$ hypertension among hypertensive patients referred for blood control evaluation by 24-h ABPM $(n=636)$. 
Table 1. General characteristics of true resistant hypertensive patients.

\begin{tabular}{|c|c|}
\hline Variables & $\begin{array}{c}\text { All } \\
\mathrm{n}=60\end{array}$ \\
\hline Age, years & $52.1 \pm 10.1$ \\
\hline Gender, n (\%) M & $42(70)$ \\
\hline $\mathrm{F}$ & $18(30)$ \\
\hline \multicolumn{2}{|l|}{ Education level, n (\%) } \\
\hline Primary/Secondary & $16(26.7)$ \\
\hline Superior/University & $44(73.3)$ \\
\hline \multicolumn{2}{|l|}{ Symptoms, n (\%) } \\
\hline Headache & $26(43.3)$ \\
\hline Chest pain & $5(8.3)$ \\
\hline Dyspnoea & $5(8.3)$ \\
\hline Vertigo & $4(6.7)$ \\
\hline BMI, $\mathrm{Kg} / \mathrm{m}^{2}$ & $30 \pm 6$ \\
\hline FPG, mg/dL & $132.8 \pm 52.1$ \\
\hline Uricacid, mg/dL & $7.4 \pm 1.7$ \\
\hline $\mathrm{CRP}, \mathrm{mg} / \mathrm{L}$ & $6(4.2-6.8)$ \\
\hline Creatinine, $\mathrm{mg} / \mathrm{dL}$ & $1.4(1.3-1.9)$ \\
\hline MDRD-eGFR, $\mathrm{mL} / \mathrm{min} / 1.73 \mathrm{~m}^{2}$ & $74 \pm 25.3$ \\
\hline $\mathrm{TC}, \mathrm{mg} / \mathrm{dL}$ & $199.2 \pm 53.9$ \\
\hline LDL-c, mg/dL & $128.9 \pm 45.9$ \\
\hline HDL-c, mg/dL & $47.1 \pm 35.6$ \\
\hline $\mathrm{TG}, \mathrm{mg} / \mathrm{dL}$ & $115.3 \pm 61.8$ \\
\hline Sodium, mEq/L & $139.8 \pm 7.0$ \\
\hline Potassium, mEq/L & $3.7 \pm 0.7$ \\
\hline
\end{tabular}

Data are expressed as mean \pm standard deviation, median(interquartile range), absolute (n) and relative (in percent) frequency. Abbreviations: M, males F, females BMI, body mass index FPG, fasting plasma glucose MDRD, modification of diet in renal diseases eGFR, estimated glomerular filtration rate TC, total cholesterol LDL-c, low-density lipoprotein-cholesterol HDL-c, high-density lipoprotein-cholesterol.

type 1 receptor blockers (ARAs) (43.4\%), and beta-blockers (BB) (28.3\%). Antihypertensive drug regimen with 3,4 and 5 drugs was observed in 32 (53.3\%), 26 (43.4\%), and $2(3.3 \%)$, respectively.

$\mathrm{BP}$ values by office $\mathrm{BP}$ and $24-\mathrm{h}$ ABP measurements are given in Table 3 . Mean values of office SBP, and DBP were $167.3 \pm 22.3 \mathrm{mmHg}$, and $100.6 \pm 15.6$ $\mathrm{mmHg}$, respectively. Mean values for 24 -h SBP and DBP were $142.3 \pm 13.8$ $\mathrm{mmHg}$ and $87.5 \pm 10.4 \mathrm{mmHg}$, respectively; values for diurnal SBP and DBP were $144.4 \pm 13.3 \mathrm{mmHg}$ and $89.8 \pm 10.4 \mathrm{mmHg}$, respectively. Values for nocturnal SBP, DBP, and HR, were $135.9 \pm 17.6 \mathrm{mmHg}$ and $81.0 \pm 10.4 \mathrm{mmHg}$, 
Table 2. Hypertension characteristics and therapeutic regimens of true resistant hypertensive patients.

\begin{tabular}{lc}
\multicolumn{1}{c}{ Variables } & All \\
& $\mathrm{n}=60$ \\
\hline Antihypertensive drug duration, months & $13.0(8.7-17.4)$ \\
Antihypertensive drug classes, $\mathrm{n}(\%)$ & $60(100)$ \\
CCB & $59(98.3)$ \\
Thiazides & $13(21.7)$ \\
Mineralocorticoid antagonists & $32(53.3)$ \\
ACEIs & $27(45.0)$ \\
ARBs & $17(28.3)$ \\
Beta-blockers & \\
Antihypertensivedrugregimen, $\mathrm{n}(\%)$ & $32(53.3)$ \\
3 drugs & $26(43.3)$ \\
4 drugs & $2(3.3)$ \\
5 drugs & \\
\hline
\end{tabular}

Data are expressed as mean \pm standard deviation, median (interquartile range), absolute (n) and relative (in percent) frequency. Abbreviations: HT, hypertension CCB, calcium channel blockers RAS, renin angiotensin system ACEIs, angiotensin converting enzyme inhibitors ARBs, angiotensin type 1 receptor blockers.

Table 3. Mean values of office and 24-h ambulatory blood pressure measurements of true resistant hypertensive patients $(n=60)$.

\begin{tabular}{cccccc}
\hline \multicolumn{5}{c}{ Office BP } & \multicolumn{5}{c}{ 24-h ABPM } \\
\hline & & $24-\mathrm{h}$ & Daytime & Nighttime & $\mathrm{P}$ \\
\hline SBP, mmHg & $167.3 \pm 22.3$ & $142.3 \pm 13.8$ & $144.4 \pm 13.3$ & $135.9 \pm 17.6$ & 0.001 \\
DBP, mmHg & $100.6 \pm 15.6$ & $87.5 \pm 10.4$ & $89.8 \pm 10.4$ & $81.0 \pm 10.4$ & 0.001 \\
MAP, mmHg & $122.8 \pm 15.6$ & $105.8 \pm 10.3$ & $106.9 \pm 13.0$ & $99.3 \pm 12.1$ & 0.001 \\
PP, mmHg & $66.8 \pm 19.7$ & $54.8 \pm 11.3$ & $54.6 \pm 11.1$ & $54.9 \pm 11.6$ & 0.521 \\
\hline
\end{tabular}

Data are expressed as mean \pm standard deviation. Abbreviations: BP, blood pressure ABPM, ambulatory blood pressure monitoring SBP, systolic blood pressure DBP, diastolic blood pressure MAP, mean blood pressure PP, pulse pressure HR, heart rate.

respectively. Mean 24-h ABPM measurement values were significantly lower than office BP measurement ones. Nycthemeral BP profile was characterized by non-dipping and reverse dipping in $28(46.7 \%)$ and 23 (38.3\%), respectively (Figure 2).

- Cardiovascular risk factor, target organ damage (TOD) profile of true RH patients

Cardiovascular risk factors (CVRF) most frequently observed among true RH patients were proteinuria (53.3\%), overweight $(46.7 \%)$, inflammation $(40.4 \%)$, and obesity (35.0) (Table 4). High/very high 10 years global CV risk was observed in $20(33.4 \%)$ patients. LVH was observed in 47 patients $(78.3 \%)$ with concentric and eccentric geometry in 35 (58.3\%) and 12 (20.0) of them, respectively. Reduced kidney function and advanced hypertensive retinopathy were 

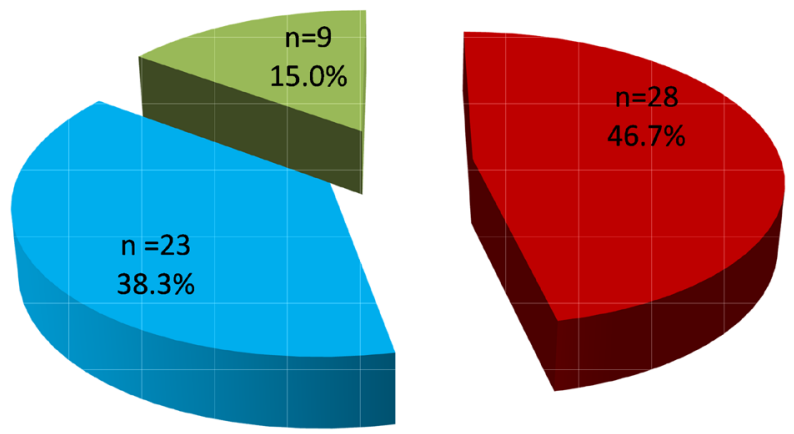

\section{Non dipping}

Normal dipping

Reverse dipping

Figure 2. Dipping status of true resistant hypertensive patients $(n=60)$.

Table 4. Cardiovascular risk factor profile, target organ damage and global cardiovascular risk of true resistant hypertensive patients.

\begin{tabular}{cc}
\hline Variables & $\begin{array}{c}\text { All } \\
\mathrm{n}=60\end{array}$ \\
\hline CVRF profile, $\mathbf{n}(\%)$ & $43(71.7)$ \\
Older age, $\mathrm{n}(\%)$ & $28(46.7)$ \\
Overweight, $\mathrm{n}(\%)$ & $21(35.0)$ \\
Obesity, n (\%) & $30(50.0)$ \\
Dyslipidemia, $\mathrm{n}(\%)$ & $26(43.3)$ \\
Diabetes, $\mathrm{n}(\%)$ & $23(40.4)$ \\
Inflammation, $\mathrm{n}(\%)$ & \\
Target organ damage, $\mathbf{n}(\%)$ & $17(28.3)$ \\
Low eGFR, $\mathrm{n}(\%)$ & $32(53.3)$ \\
Dipstick proteinuria, $\mathrm{n}(\%)$ & $47(78.3)$ \\
LVH, $\mathrm{n}(\%)$ & $35(58.3)$ \\
Concentric & $12(20.0)$ \\
Eccentric & $7(11.9)$ \\
High/very high & $40(66.7)$ \\
Ten years global CV risk, $\mathbf{n}(\%)$ & $20(33.3)$ \\
Mdvanced hypertensive retinopathy, $\mathrm{n}(\%)$ & \\
\hline
\end{tabular}

Data are expressed as absolute (n) and relative (in percent) frequency. Abbreviations: CVRF, cardiovascular risk factor LVH, left ventricular hypertrophy.

found in 17 (28.3\%) and 7 (11.9\%) patients, respectively.

- Correlates of SBP among patients with true RH

Given the small number of patients with apparent - RH $(n=15)$, logistic regression analysis was not applicable; thus, we assessed correlates of 24-h ABPM SBP among true RH patients as a proxy of true RH in simple and multiple linear regression analysis. In simple linear regression analysis, 24-h SBP was positively and significantly correlated with BMI $(r=0.451 ; p=0.012)$, uric acid $(r=0.318$; $\mathrm{p}=0.024)$, and blood glucose $(\mathrm{r}=0.354 ; \mathrm{p}=0.036)$ whereas negatively and sig- 
nificantly correlated with eGFR $(\mathrm{r}=0.446 ; \mathrm{p}=0.012)$ and HDL-c $(\mathrm{r}=0.467 ; \mathrm{p}=$ 0.009). In multiple linear regression analysis (Table 5), correlations remained statistically significant for only BMI, FPG and eGFR; the model explained $67.2 \%$ of SBP variations. Each one unit increase in BMI $\left(1 \mathrm{Kg} / \mathrm{m}^{2}\right)$ and blood glucose $(1$ $\mathrm{mg} / \mathrm{dl}$ ) was associated with $0.56 \mathrm{mmHg}$ and $0.22 \mathrm{mmHg}$ increase in SBP, respectively; however, each one unit decline in eGFR $\left(1 \mathrm{~mL} / \mathrm{min} / 1.73 \mathrm{~m}^{2}\right)$ was associated with $0.93 \mathrm{mmHg}$ increase in SBP.

\section{Discussion}

The main findings of the present study are as follows. First, clinically suspected $\mathrm{RH}$ and true resistant hypertension were observed in $11.7 \%$ and $9.4 \%$ of patients, respectively. Second, headache, dyspnea and chest pain were the symptoms most frequently reported by true $\mathrm{RH}$ patients. Third, true $\mathrm{RH}$ was associated with a non-dipping BP pattern. Fourth, BMI, uric acid, blood glucose were positively whereas eGFR and HDL-c negatively associated with SBP in true RH patients in multiple linear regression analysis.

Clinically suspected RH by office BP measurements was observed in $11.7 \%$ of patients referred for BP control evaluation by ABPM. Our finding is somewhat closest to that of $15 \%$ to $18 \%$ found in clinic-based reports [22] [23]. Higher prevalence of RHhas been observed in clinic-based samples when an at-risk group is selected, such as patients with treated hypertension and chronic kidney disease (CKD) for example, patients with treated hypertension and chronic kidney disease (CKD), is selected [24] [25] [26] [27]. This higher prevalence could be explained by the selection of patients with demographic and comorbidity characteristics that place them at high risk for the fatal and nonfatal CVD outcomes. Given the highest prevalence rates of uncontrolled hypertension in Africa, the burden of RH could be most likely increased across the continent [28] [29]. In the absence of accurate epidemiology capturing the burden of RH in Africa, a recent meta-analysis by Nanseu et al. [1] reported an overall prevalence

Table 5. Correlates of 24-h ambulatory systolic blood pressure (SBP) of resistant hypertensive patients in multiple regression analysis.

\begin{tabular}{cccc}
\hline Variables & $\beta$ & SE & P \\
\hline (Constant) & 122.31 & 20.63 & 0.000 \\
MDRD-eGFR, $\mathrm{mL} / \mathrm{min} / 1.73 \mathrm{~m}^{2}$ & -0.93 & 0.76 & 0.022 \\
HDL-c, $\mathrm{mg} / \mathrm{Dl}$ & -0.54 & 0.42 & 0.208 \\
FPG, $\mathrm{mg} / \mathrm{dL}$ & 0.22 & 0.36 & 0,024 \\
BMI, Kg/m & 0.56 & 0.30 & 0.007 \\
Uricacid, $\mathrm{mg} / \mathrm{dL}$ & 0.45 & 1.05 & 0.294 \\
$\mathrm{R}^{2}=0.672$ & & & \\
\hline
\end{tabular}

Abbreviations: SE, standard error MDRD, modification diet in renal disease eGFR, estimated glomerular filtration HDL-c, high density lipoprotein-cholesterol FPG, fasting plasma glucose BMI, body mass index $\mathrm{R}^{2}$, determination coefficient. 
of clinic RH of $12.1 \%$ (95\% CI $8.0 \%$ to $17.7 \%$ ). The prevalence of RH was $11.7 \%$ (95\% CI $9.3 \%$ to $14.6 \%$ ) in Cameroon, $4.9 \%$ (95\% CI $3.4 \%$ to $7.1 \%$ ) in Nigeria, $14.3 \%$ (95\% CI $7.9 \%$ to $24.6 \%$ ) in Lesotho and $19.0 \%$ (95\% CI $17.4 \%$ to $20.7 \%$ ) in Algeria [1]. The observed disparity in $\mathrm{RH}$ prevalence study between studies could be explained by differences in the definition of $\mathrm{RH}$ used, the characteristics of studied populations, the availability of ABPM, the duration of hypertension and the period when the study was conducted since the burden of hypertension varies overtime [1]. With regard to the period when the studies were conducted, the study from Cameroon was conducted 25 years ago, that from Nigeria 13 years ago, the one from Burkina Faso 4 years ago and those from Lesotho and Algeria 3 and 2 years back, respectively [1]. In Cameroon, the mean duration of hypertension since diagnosis was $7 \pm 5$ years in men and $8 \pm 6$ years in women; in Burkina Faso, 11 (10.9\%) patients with $\mathrm{RH}$ were followed-up for not more than 1 year and 15 (14.9\%) for at least 10 years [1].

In the present study, the frequency of true resistant hypertension was $9.4 \%$. Our observed frequency is lower than that reported by several studies conducted in Europe and North America [30] as well as in Asia [31] [32]. In the Controlled Onset Verapamil Investigation of Cardiovascular Endpoints, the prevalence of true RH was $18 \%$ [30]. In a study from an Asian population, Naseem et al., [32] reported a prevalence of true $\mathrm{RH}$ of $12 \%$. In SSA, only one study by Yaméogo et al. [33] from Burkina Faso undertook the ABPM to exclude white-coat-related $\mathrm{RH}$ and found a prevalence of true $\mathrm{RH}$ of $14.6 \%$ (95\% CI $12.2 \%$ to $17.4 \%$ ). The reasons underlying the disparity in true $\mathrm{RH}$ prevalence between studies have been already discussed in the section clinic $\mathrm{RH}$.

Headache followed by dyspnea and precordial chest pain were symptoms most frequently reported by true $\mathrm{RH}$ patients in the present study. In SSA, only one study by Yaméogo [33] from Burkina Faso found headaches (11.9\%), dizziness $(9.9 \%)$, precordial chest pain (8.9\%) and hemiplegia (4.1\%) as signs and symptoms most frequently reported by true $\mathrm{RH}$ patients. All these signs and symptoms do translate the severity of tissue and organ failure associated with true RH.

True $\mathrm{RH}$ was associated in the present study with a non-dipping pattern. In a cohort prospective study comparing the prevalence of nocturnal hypertension and non-dipping among black with and without RH, Irvin et al. [34]found that participants with $\mathrm{RH}$ were more likely to have nocturnal hypertension (prevalence ratio, 1.20 [1.03 - 1.43]) and non-dipping (prevalence ratio, 1.25 [1.09 1.43]) after adjustment for confounders. Furthermore, Muxfeldt et al. [35] demonstrated that subjects with true $\mathrm{RH}$ compared to white coat $\mathrm{RH}$ had lower nocturnal systolic $\mathrm{BP}$ reductions $(6.4 \pm 8.8$ versus $9.8 \pm 7.5 \mathrm{mmHg}, \mathrm{P}=0.0004)$, lower nocturnal DBP $(10.4 \pm 9.6$ versus $13.6 \pm 9.2 \mathrm{mmHg}, \mathrm{P}=0.001)$, and a higher percentage of non-dippers $(68.7 \%$ versus $49.6 \%, \mathrm{P}=0.001)$. Similarly, Friedman and Logan [36] showed that the prevalence of non-dipping among normotensive, controlled hypertensive, and resistant hypertensive subjects was $25.0 \%, 42.3 \%$, and $61.5 \%$, respectively $(\mathrm{P}=0.006)$. Given the high prevalence of 
nocturnal hypertension and non-dipping $\mathrm{BP}$ among individuals with TRH, treatment strategies directed at lowering nighttime BP and increasing BP dipping may be warranted. One prior randomized trial suggests that taking antihypertensive medication at bedtime may lower nighttime SBP to a greater extent than taking it in the morning [37]. As diuretic treatment was associated with a lower prevalence of non-dipping, pressure natriuresis may play a role in non-dipping where BP remains high during sleeping hours to counteract sodium retention during the day [38]. Diuretics may be especially beneficial in blacks, a population with a high prevalence of salt-sensitive hypertension [38].

BMI, blood glucose, uric acid and were positively correlated to SBP in true resistant hypertension patients in the present study. The pathogenetic link underlying the relationship between BMI, blood glucose, uric acid and RH is insulin resistance and subsequent hyperinsulinemia [39] [40]. Indeed, these metabolic risk in isolation or combined as metabolic syndrome are factors known to negatively interfere with BP control via endothelial dysfunction [41]. Obesity, the sixth most important predisposing factor for RH [42], elevates, solely or in interaction with blood glucose and uric acid [41], the need for increased number of antihypertensive medications and also increases tendency of never achieving required BP control [43]. Increased body weight predisposes to true $\mathrm{RH}$ by causing decreased sodium excretion, insulin resistance, increased activity of sympathetic nervous system and lastly renal injury by the activation of the renin-angiotensin system and subsequent oxidative stress [44] [45].

In multiple regression analysis, HDL-c and eGFR were negatively correlated with SBP among true RH patients in the present study. Low HDL-c is a well-known marker of insulin-resistance [41] and negatively interferes with BP control through above-mentioned biochemical and metabolic pathways. Most studies on the relationship between kidney function and $\mathrm{RH}$ were cross-sectional ones and found that the prevalence of true RH is substantially higher in patients with CKD, estimated to be $40 \%$ of hypertensive participants in the Chronic Renal Insufficiency Cohort (CRIC) Study. Approximately 50\% had BP that was not at target on three or more medications, and the other one half had BP that was at target on four or more medications [46]. In the CRIC Study, participants with CKD and treatment-rHTN had a $38 \%$ higher risk of cardiovascular events or all-cause mortality and a $28 \%$ higher risk of ESRD or $50 \%$ decline in GFR [46]. Importantly, non-dipping occurs in $49 \%-82 \%$ of hypertensive patients with CKD and is associated with progression of CKD [46]. In a recent prospective study on the relationship between kidney function and RH, Kaboré et al. [47] reported a mean eGFR decline using the MDRD equation during follow-up of $1.5 \pm 2.9 \mathrm{~mL} / \mathrm{min} / 1.73 \mathrm{~m}^{2}$ per year. After adjusting for age, sex, obesity, diabetes, and cardiovascular history, the odds ratios (ORs) for new-onset treatment-RH associated with a mean eGFR level, per $15 \mathrm{~mL} / \mathrm{min} / 1.73 \mathrm{~m}^{2}$ drop, were 1.23 [10.91 - 1.64] vs controlled hypertension and 1.10 [0.83 - 1.45] vs uncontrolled non-RH. Apart from renin angiotensin system activation and uremic toxins, water and salt retention via high salt diet has been reported as the main culprit 
causing resistance to antihypertensive agents by increment of BP and/or blunting the BP-lowering effect of antihypertensive agents [46].

The interpretation should take into account of some limitations. First, the study design precludes the establishment of any temporal relationship between variables of interest. Second, the small sample size did not confer sufficient power to statistical tests in detecting potential associations between variable of interest. Third, the hospital-based design of the present study did allow the generalization of our results to the whole true hypertensive patients.

\section{Conclusion}

True resistant hypertension was a common finding among clinical resistant hypertension patients and associated with a high 10 years global cardiovascular risk explained by the coexistence of modifiable traditional risk factors and target organ damage. The present study highlights the diagnostic and prognostic importance of 24-h ABPM among clinical resistant hypertension patients.

\section{Acknowledgements}

The authors gratefully thank all the medical and administrative staff of all participating Centers (Ngaliema Medical Center, Kinshasa Medical Center, Diamant Medical Center and "Médecins de Nuit" Center) for their commitment and facilities obtained during the conduct of the present study.

\section{Author's Contribution}

DK participated in survey conception, data collection and management and reviewed the manuscript; drafted the manuscript.

FBL participated in survey conception, data analysis and drafted the manuscript.

YL participated in survey conception and reviewed the manuscript; drafted the manuscript.

JRRM participated in survey conception, data analysis and revised the manuscript.

AN conducted data management and analysis and reviewed the manuscript.

NO reviewed the manuscript.

TM reviewed the manuscript.

DM reviewed the manuscript.

GN reviewed the manuscript.

FK reviewed the manuscript.

EVK reviewed the manuscript.

JRM reviewed the manuscript.

\section{Conflicts of Interest}

The authors declare no conflicts of interest regarding the publication of this paper. 


\section{References}

[1] Nansseu, J.R., Noubiap, J.J., Mengnjo, M.K., Aminde, L.N., Essouma, M., Jingi, A.M. and Bigna, J.J. (2016) The Highly Neglected Burden of Resistant Hypertension in Africa: A Systematic Review and Meta-Analysis. BMJ Open, 6, e011452. https://doi.org/10.1136/bmjopen-2016-011452

[2] Chobanian, A.V., Bakris, G.L., Black, H.R., Cushman, W.C., Green, L.A., Izzo, J.L., et al. (2003) Seventh Report of the Joint National Committee (JNC7) on Prevention, Detection, Evaluation, and Treatment of High Blood Pressure. Hypertension, 42, 1206-1252. https://doi.org/10.1161/01.HYP.0000107251.49515.c2

[3] Daugherty, S.L., Powers, I.D., Magid, D.J., Tavel, H.M., Massoudi, F.A., Margolis, K.L., et al. (2012) Incidence and Prognosis of Resistant Hypertension in Hypertensive Patients. Circulation, 125, 1625-1642. https://doi.org/10.1161/CIRCULATIONAHA.111.068064

[4] Hanus, K.M., Prejbisz, A., Gąsowski, J., Klocek, M., Topór-Mądry, R., Leśniak, W., et al. (2017) Relationship between Gender and Clinical Characteristics, Associated Factors, and Hypertension Treatment in Patients with Resistant Hypertension. Kardiologia Polska, 75, 421-431. https://doi.org/10.5603/KP.a2017.0020

[5] Syrseloudis, D., Andrikou, I., Andrikou, E., Dimitriadis, K. and Stefanadis, C. (2011) Ambulatory Blood Pressure Monitoring in Resistant Hypertension. International Journal of Hypertension, 2011, Article ID: 285612. https://doi.org/10.4061/2011/285612

[6] Oliveras, A., Armario, P., Hernández-Del Rey, R., Arroyo, J.A., Poch, E., Larrousse, M., et al. (2010) Urinary Albumin Excretion Is Associated with True Resistant Hypertension. Journal of Human Hypertension, 24, 27-33. https://doi.org/10.1038/jhh.2009.35

[7] Bayauli, M.P., M’Buyamba-Kayama, J.R., Ngoyi, N.G., Lepira, F.B., Kayembe, K.P., Lemogoum, D., et al. (2018) Trends in Prevalence of Obesity and Hypertension in an Urban Congolese Community. Journal Epidemiological Research, 4, 33-40. https://doi.org/10.5430/jer.v4n1p33

[8] Kianu, B., Mpembele, E., Kintoki, E.V., Makulo, J.R., Kiazayawoko, F.Z., Manyebwa, K.J.D.D., et al. (2015) Rates of Hypertension Prevalence, Awareness, Treatment, and Control in Congolese South West Port City. The Influence of Gender According to Groups. Global Journal of Medical Research, 15, 1-8.

[9] Katchunga, P.B., Mirindi, P., Baleke, P., Ntaburhe, T., Twagirumukiza, M. and M'Buyamba-Kabangu, J.R. (2019) The Trend in Blood Pressure and Hypertension Prevalence in the General Population of South Kivu between 2012 and 2016: Results from Two Representative Cross-Sectional Surveys-The Bukavu Observational Study. PLoS ONE, 14, e0219377. https://doi.org/10.1371/journal.pone.0219377

[10] M’Buyamba-Kabangu, J.R., Biswika, R.T., Thijs, L., Tshimanga, G.M., Ngalula, F.M., Disahi, T., et al. (2009) In-Hospital Mortality among Black Patients Admitted for Hypertension-Related Disorders in Mbuji-Mayi, Congo. American Journal of Hypertension, 22, 643-648. https://doi.org/10.1038/ajh.2009.47

[11] Kika, T.M., Lepira, F.B., Kayembe, P.K., Makulo, J.R., Sumaili, E.K., Kintoki, E.V. and M'Buyamba-Kabangu, J.R. (2016) Uncontrolled Hypertension among Patients Managed in Primary Healthcare Facilities in Kinshasa, Democratic Republic of the Congo. Cardiovascular Journal of Africa, 27, 361-366.

https://doi.org/10.5830/CVJA-2016-036

[12] Mvunzi, T.S., Lubenga, Y., Lepira, F.B., Makulo, J.R., Nkodila, A., Kuntonda, D.K., et al. (2017) Prevalence of Circadian Blood Pressure Patterns and Factors Asso- 
ciated with Non-Dipping among Black Patients with Untreated and Treated Hypertension: A Cross-Sectional Study. WJCD, 7, 399.

https://doi.org/10.4236/wjcd.2017.711038

[13] Ilunga, C.K., Lepira, F.B., Makulo, J.R., Lubenga, Y., Mvunzi, T., Utshudi, N., et al. (2019) Interdialytic 24-Hours Ambulatory Blood Pressure versus Dialysis Unit Blood Pressure for the Diagnosis of Electrocardiographic-Left Ventricular Hypertrophy in Chronic Hemodialysis Black Patients. WJCD, 9, 846.

https://doi.org/10.4236/wjcd.2019.911075

[14] American Diabetes Association (2008) Position Statement, Diagnosis and Classification of Diabetes Mellitus. Diabetes Care, 31, S55-S60.

https://doi.org/10.2337/dc08-S055

[15] National Heart Lung and Blood Institute (2001) Executive Summary of the Third Report of National Cholesterol Education Program (NCEP) Expert Panel on Detection, Evaluation, and Treatment of High Blood Cholesterol in Adults (Adult Treatment Panel III). The Journal of the American Medical Association, 285, 2486-2497. https://doi.org/10.1001/jama.285.19.2486

[16] Levey, A.S., Greene, T. and Kusek, J.W. (2000) A Simplified Equation to Predict Glomerular Filtration Rate from Serum Creatinine. Journal of the American Society of Nephrology, 11, A0828.

[17] Levey, A.S., Atkins, R., Coresh, J., Cohen, E.P., Collins, A.J., Eckardt, K.U., et al. (2007) Chronic Kidney Disease as a Global Public Health Problem: Approaches and Initiatives-A Position Statement from Kidney Disease Improving Global Outcomes. Kidney International, 72, 247-259. https://doi.org/10.1038/sj.ki.5002343

[18] Devereux, R.B., Alonso, D.R., Lucas, E.M., Gottlieb, E., Sachs, I. and Reichek, N. (1986) Echocardiographic Assessment of Left Ventricular Hypertrophy: Comparison to Necropsy Findings. American Journal of Cardiology, 57, 450-458. https://doi.org/10.1016/0002-9149(86)90771-X

[19] Lang, R.M., Bierig, M., Devereux, R.B., Flachskampf, F.A., Foster, E., Pellikka, P.A., et al. (2005) Recommendations for Chamber Quantification: A Report from the American Society of Echocardiography's Guidelines and Standards Committee and the Chamber Quantification Writing Group, Developed in Conjunction with the European Association of Echocardiography, a Branch of the European Society of Cardiology. Journal of the American Society of Echocardiography, 18, 1440-1463. https://doi.org/10.1016/j.echo.2005.10.005

[20] de la Sierra, A., Redon, J., Banegas, J.R., Segura, J., Parati, G., Gorostidi, M., et al. (2009) Prevalence and Factors Associated with Circadian Blood Pressure Patterns in Hypertensive Patients. Hypertesion, 53, 466-472.

https://doi.org/10.1161/HYPERTENSIONAHA.108.124008

[21] Mancia, G., Williams, B., Mancia, G., Spiering, W., AgabitiRosei, E., Azizi, M., Burnier, M., et al. (2018) Practice Guidelines for the Management of Arterial Hypertension of the European Society of Hypertension and the European Society of Cardiology: ESH/ESC Task Force for the Management of Arterial Hypertension. Journal of Hypertension, 36, 2284-2309. https://doi.org/10.1097/HJH.0000000000001961

[22] Borghi, C., Tubach, F., De Backer, G., Dallongeville, J., Guallar, E., Medina, J., et al. (2016) Lack of Control of Hypertension in Primary Cardiovascular Disease Prevention in Europe: Results from the EURIKA Study. International Journal of Cardiology, 218, 83-88. https://doi.org/10.1016/j.ijcard.2016.05.044

[23] de la Sierra, A., Segura, J., Banegas, J.R., Gorostidi, M., de la Cruz, J.J., Armario, P., et al. (2011) Clinical Features of 8295 Patients with Resistant Hypertension Classi- 
fied on the Basis of Ambulatory Blood Pressure Monitoring. Hypertension, 57, 898-902. https://doi.org/10.1161/HYPERTENSIONAHA.110.168948

[24] Thomas, G., Xie, D., Chen, H.Y., Anderson, A.H., Appel, L.J., Bodana, S., et al. (2016) CRIC Study Investigators. Prevalence and Prognostic Significance of Apparent Treatment Resistant Hypertension in Chronic Kidney Disease: Report from the Chronic Renal Insufficiency Cohort Study. Hypertension, 67, 387-396. https://doi.org/10.1161/HYPERTENSIONAHA.115.06487

[25] Tanner, R.M., Calhoun, D.A., Bell, E.K., Bowling, C.B., Gutiérrez, O.M., Irvin, M.R., et al. (2013) Prevalence of Apparent Treatment-Resistant Hypertension among Individuals with CKD. Clinical Journal of the American Society of Nephrology, 8, 1583-1590. https://doi.org/10.2215/CJN.00550113

[26] Lamirault, G., Artifoni, M., Daniel, M., Barber-Chamoux, N. and Nantes University Hospital Working Group on Hypertension (2020) Resistant Hypertension: New Insights. Current Hypertension Reviews, 16, 61-72. https://doi.org/10.2174/1573402115666191011111402

[27] Noubiap, J.J., Nansseu, J.R., Nyaga, U.F., Sime, P.S., Francis, I. and Bigna, J.J. (2019) Global Prevalence of Resistant Hypertension: A Meta-Analysis of Data from 3.2 Million Patients. Heart, 105, 98-105. https://doi.org/10.1136/heartjnl-2018-313599

[28] Ataklte, F., Erqou, S., Kaptoge, S., et al. (2015) Burden of Undiagnosed Hypertension in Sub-Saharan Africa: A Systematic Review and Meta-Analysis. Hypertension, 65, 291-298. https://doi.org/10.1161/HYPERTENSIONAHA.114.04394

[29] Dzudie, A., Kengne, A.P., Muna, W.F., Ba, H., Menanga, A., KouamKouam, C., et al. (2012) Prevalence, Awareness, Treatment and Control of Hypertension in a Self-Selected Sub-Saharan African Urban Population: A Cross-Sectional Study. BMJ Open, 2, pii: e001217. https://doi.org/10.1136/bmjopen-2012-001217

[30] Black, H.R., Elliott, W.J., Grandits, G., Grambsch, P., Lucente, T., Neaton, J.D., et al. (2003) Principal Results of the Controlled Onset Verapamil Investigation of Cardiovascular End Points (CONVINCE) Trial. JAMA, 289, 2073-2082. https://doi.org/10.1001/jama.289.16.2073

[31] Naseem, R., Adama, A.M., Khanb, F., Dossal, A., Khan, I., Khan, A., et al. (2017) Prevalence and Characteristics of Resistant Hypertensive Patients in an Asian Population. Indian Heart Journal, 69, 442-446. https://doi.org/10.1016/j.ihj.2017.01.012

[32] Choi, S.I., Kim, S.K., Park, S., Kim, J.H., Ihm, S.H., Kim, G.I., et al. (2016) Prevalence of Resistant Hypertension and Associated Factors for Blood Pressure Control Status with Optimal Medical Therapy Using Korean Ambulatory Blood Pressure Monitoring Registry Data. Clinical Hypertension, 22, 8.

https://doi.org/10.1186/s40885-016-0045-x

[33] Yaméogo, N.V., Samadoulougou, A.K., Kagambèga, L.J., Millogo, G.R., Yaméogo, A.A., Kologo, K.J., et al. (2014) Epidemiological Characteristics and Clinical Features of Black African Subject's Resistant Hypertension. Annales de Cardiologie et d Angéiologie (Paris), 63, 83-88. https://doi.org/10.1016/j.ancard.2014.01.002

[34] Irvin, R., Booth, J.N., Sims, M., Bress, A.P., Abdalla, M., Shimbo, D., et al. (2018) The Association of Nocturnal Hypertension and Non-Dipping Blood Pressure with Treatment-Resistant Hypertension: The Jackson Heart Study. Clinical Hypertension, 20, 438-446. https://doi.org/10.1111/jch.13199

[35] Muxfeldt, E.S., Bloch, K.V., Nogueira, A.R. and Salles, G.F. (2003) Twenty-Four Hour Ambulatory Blood Pressure Monitoring Pattern of Resistant Hypertension. 
Blood Pressure Monitoring, 8, 181-185.

https://doi.org/10.1097/00126097-200310000-00001

[36] Friedman, O. and Logan, A.G. (2009) Nocturnal Blood Pressure Profiles among Normotensive, Controlled Hypertensive and Refractory Hypertensive Subjects. The Canadian Journal of Cardiology, 25, e312-e316. https://doi.org/10.1016/S0828-282X(09)70142-4

[37] Hermida, R.C., Ayala, D.E., Fernández, J.R. and Calvo, C. (2008) Chronotherapy Improves Blood Pressure Control and Reverts the Non-Dipper Pattern in Patients with Resistant Hypertension. Hypertension, 51, 69-76. https://doi.org/10.1161/HYPERTENSIONAHA.107.096933

[38] Sachdeva, A. and Weder, A.B. (2006) Nocturnal Sodium Excretion, Blood Pressure Dipping, and Sodium Sensitivity. Hypertension, 48, 527-533. https://doi.org/10.1161/01.HYP.0000240268.37379.7c

[39] Uzu, T., Nishimura, M., Fujii, T., Takeji, M., Kuroda, S., Nakamura, S., et al. (1998) Changes in the Circadian Rhythm of Blood Pressure in Primary Aldosteronism in Response to Dietary Sodium Restriction and Adrenalectomy. Journal of Hypertension, 16, 1745-1748. https://doi.org/10.1097/00004872-199816120-00006

[40] Rao, A., Pandya, V. and Whaley-Connell, A. (2015) Obesity and Insulin Resistance in Resistant Hypertension. Advances in Chronic Kidney Disease, 22, 211-217. https://doi.org/10.1053/j.ackd.2014.12.004

[41] Dawson, J. and Wyss, A. (2017) Chicken or the Egg? Hyperuricemia, Insulin Resistance, and Hypertension. Hypertension, 70, 698-699. https://doi.org/10.1161/HYPERTENSIONAHA.117.09685

[42] Catharina, A.S., Modolo, R., Ritter, A.M.V., Sabbatini, A.R., Lopes, H.F., Moreno Junior, H., Faria, A., et al. (2018) Metabolic Syndrome-Related Features in Controlled and Resistant Hypertensive Subjects. Arquivos Brasileiros de Cardiologia, 110, 514-521. https://doi.org/10.5935/abc.20180076

[43] Haslam, D.W. and James, W.P. (2005) Obesity. The Lancet, 366, 1197-1209. https://doi.org/10.1016/S0140-6736(05)67483-1

[44] Bramlage, P., Pittrow, D., Wittchen, H.U., Kirch, W., Boehler, S., Lehnert, H., et al. (2004) Hypertension in Overweight and Obese Primary Care Patients Is Highly Prevalent and Poorly Controlled. American Journal of Hypertension, 17, 904-910. https://doi.org/10.1016/j.amjhyper.2004.05.017

[45] Hall, J.E. (2003) The Kidney, Hypertension and Obesity. Hypertension, 41, 625-633. https://doi.org/10.1161/01.HYP.0000052314.95497.78

[46] Braam, B., Taler, S.J., Rahman, M., Fillaus, J.A., Greco, B.A., Forman, J.P., et al. (2017) Recognition and Management of Resistant Hypertension. Clinical Journal of the American Society of Nephrology, 12, 524-535. https://doi.org/10.2215/CJN.06180616

[47] Kaboré, J., Metzger, M., Helmer, C., Berr, C., Tzourio, C., Massy, Z.A., et al. (2016) Kidney Function Decline and Apparent Treatment-Resistant Hypertension in the Elderly. PLOS ONE, 11, e0146056. https://doi.org/10.1371/journal.pone.0146056 